\title{
An Evaluation Model of Academic Performance of Electronic Information Science and Technology Based on Complex Network Theory
}

\author{
Qingyu Zou ${ }^{1, a}$ and Dejun Liu ${ }^{1, b^{*}}$ \\ ${ }^{1}$ College of Electrical and Information Engineering of Beihua University, Jilin, China \\ azouqingyu2002@126.com, bdejunliu@126.com
}

\begin{abstract}
Keywords: Academic performance evaluation; Network model; Complex network; Model
\end{abstract}
\begin{abstract}
Student evaluation is an important element in the teaching process. Student evaluation contains many elements, the most important is the evaluation of its results. But the test scores can not dynamically respond to a student's learning state. This paper presents a student achievement evaluation model of electronic science and technology based on complex network theory. We firstly construct a curriculum influence value network using the interaction relationship between the courses of electronic science and technology. Then, the test scores of each subject are included in the curriculum influencing value network to obtain the current performance evaluation network model of students. According to the structural characteristics of current performance evaluation network model, we can evaluate the quality of students' professional training. In this article, we use this model to assess the quality of the 35 electronic science and technology graduates. The results show that the evaluation of the network model can accurately measure the quality of electronic information engineering student professional training.
\end{abstract}

\section{Introduction}

As an important part of education, teaching and curriculum evaluation, learning evaluation has been concerned by domestic and foreign experts, scholars and first-line teaching workers. An excellent performance evaluation system is an important basis for the realization of educational goals and an important basis for adjusting educational goals. It is conducive to the development of students' healthy personality and the promotion of students' all-round development. Electronic science and technology professional training with FPGA technology, embedded technology and other fields of knowledge, to engage in hardware and software system design, product development, teaching and research and technical management and other aspects of work, and has the spirit of innovation and practical ability of senior engineering and technical personnel. The current evaluation method is based on the "absolute score" to evaluate the students' learning situation. This method measures the student's learning condition by the average of an examination, and does not look at the student's learning from the perspective of the dynamic change in academic performance. It ignores the difference between the basic conditions of different students, only the basic conditions of the students play a catalytic role in the basic conditions are relatively weak but the progress of students is difficult to play a role in encouraging. Therefore, in order to accurately assess the student's learning situation, we must consider the actual results and performance changes in two aspects. In this paper, we use the influence relationship between each course and the results of each course to establish the network model of student achievement evaluation, according to the structure of the network model to measure the quality of professional personnel training[1-5].

\section{Construction of the Complex Network Model of curriculum influence}

Courses of Electronic Information Science and Technology. Electronic information science and technology is a subject used in modern technology such as computer and electronic information control and information processing. The main research are intelligent electronic system design, information processing, wireless sensor network and so on. It set up a total of 60 multi course include the circuit theory, information theory and coding, signal and system, digital signal processing, electromagnetic 
theory, embedded Systems and Application, etc. We have selected 52 important courses which affect the relationship between the students and the students, specific courses as shown in Table 1.

Table 1 Courses of electronic information engineering

\begin{tabular}{|c|c|c|c|c|c|}
\hline No. & Course name & No. & Course name & No. & Course name \\
\hline 1 & $\begin{array}{l}\text { Digital Electronic } \\
\text { Technique }\end{array}$ & 19 & $\begin{array}{l}\text { The Principle of } \\
\text { Communication }\end{array}$ & 37 & EDA practice \\
\hline 2 & $\begin{array}{c}\text { Analog Electronic } \\
\text { Technique experiment }\end{array}$ & 20 & $\begin{array}{l}\text { Embedded Systems and } \\
\text { Application }\end{array}$ & 38 & Professional internship \\
\hline 3 & $\begin{array}{c}\text { Digital Electronic } \\
\text { Technique experiment }\end{array}$ & 21 & Embedded Systems Practice & 39 & Graduation practice \\
\hline 4 & $\begin{array}{c}\text { High frequency } \\
\text { electronics Technology }\end{array}$ & 22 & $\mathrm{C}++$ Programing & 40 & Graduation design \\
\hline 5 & $\begin{array}{l}\text { EDA Technology and } \\
\text { Application } \\
\end{array}$ & 23 & Computer Networks & 41 & $\begin{array}{l}\text { Single-chip Micro-computer } \\
\text { And Interface Technology }\end{array}$ \\
\hline 6 & System-on-chip design & 24 & Digital Signal Processing & 42 & MCU interface practice \\
\hline 7 & College Foreign Language & 25 & $\begin{array}{c}\text { Electromagnetic Field } \\
\text { Theory }\end{array}$ & 43 & $\begin{array}{c}\text { Electronic technology } \\
\text { practice }\end{array}$ \\
\hline 8 & Probability and Statistics & 26 & RF electronic circuits & 44 & Document Retrieval \\
\hline 9 & $\begin{array}{l}\text { Complex Analysis and } \\
\text { Integral Transformation }\end{array}$ & 27 & $\begin{array}{c}\text { Computer simulation } \\
\text { foundation }\end{array}$ & 45 & $\begin{array}{c}\text { Innovation and quality } \\
\text { development elective }\end{array}$ \\
\hline 10 & Physics of college & 28 & Sensors Technology & 46 & College Chinese \\
\hline 11 & Circuit Theory & 29 & New Technology Topics & 47 & $\begin{array}{c}\text { University Computer } \\
\text { Foundation } \\
\end{array}$ \\
\hline 12 & $\begin{array}{l}\text { Analog Electronic } \\
\text { Technique }\end{array}$ & 30 & Wireless sensor network & 48 & $\begin{array}{c}\text { Computer programming }(\mathrm{C} \\
\text { language })\end{array}$ \\
\hline 13 & Digital electronic practice & 31 & $\begin{array}{c}\text { Introduction to the Basis of } \\
\text { Internet of Things }\end{array}$ & 49 & Advanced Mathematics \\
\hline 14 & Electronic CAD practice & 32 & $\begin{array}{l}\text { Radio Frequency Electronic } \\
\text { Identification Technology }\end{array}$ & 50 & Linear Algebra \\
\hline 15 & Electronic circuit practice & 33 & $\begin{array}{l}\text { Application Technology of } \\
\text { FPGA Engineering }\end{array}$ & 51 & $\begin{array}{l}\text { The Professional } \\
\text { Introduction }\end{array}$ \\
\hline 16 & Signal and System & 34 & $\begin{array}{c}\text { Object-oriented C ++ } \\
\text { internship }\end{array}$ & 52 & $\begin{array}{l}\text { Basic manufacturing } \\
\text { technology practice }\end{array}$ \\
\hline 17 & $\begin{array}{l}\text { DSP Technology and } \\
\text { Application }\end{array}$ & 35 & Production practice & & \\
\hline 18 & DSP practice & 36 & $\begin{array}{l}\text { Computer network } \\
\text { technology internship }\end{array}$ & & \\
\hline
\end{tabular}

Construction of Curriculum Influence Value Network Model. We construct curriculum impact weight network according to the mutual influence relationship and credit of courses. The network is a directed weight network. Node in the network is a course in Table 1. The edge of the network is influenced by the relationship, which from the first courses to the application course. The value of edges are the product of the proportion of the knowledge of first course in application course and the credit of first course. For example, circuit theory course is the first course of signal and system course. More than $20 \%$ knowledge of signal and system course are related to the knowledge of higher mathematics. Therefore, there is a point between the two nodes of circuit theory and signal and system, and the weight of edge is 0.5 . The curriculum affecting value network model of electronic information science and technology as shown in Fig. 1. 


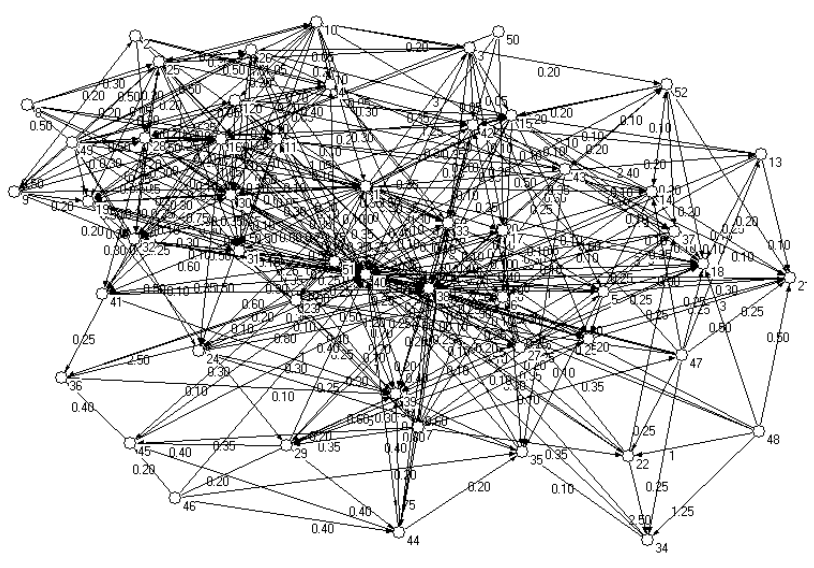

Figure 1. Curriculum influence value network model

Construction of Achievement Evaluation Network Model. The curriculum influence value network reflects the influence degree of each course of electronic information science and technology. In order to evaluate the student's academic situation, we combine the achievement of students and the value network to build the achievement evaluation network model. The weight of the edge of achievement evaluation network is equal to the product of the score of the support course and the weight of this edge in curriculum influence value network. For example, the scores of all subjects of an electronic science and technology student are shown in Table 2, and then the grade evaluation networks are shown in Fig. 2 .

Table 2 Student achievement

\begin{tabular}{|l|l|l|l|l|l|l|l|l|l|l|l|l|l|l|l|l|l|l|}
\hline Number & 1 & 2 & 3 & 4 & 5 & 6 & 7 & 8 & 9 & 0 & 1 & 2 & 3 & 4 & 5 & 6 & 7 & \\
\hline \multirow{3}{*}{ Scores } & 8 & 9 & 9 & 8 & 8 & 8 & 6 & 9 & 9 & 9 & 7 & 7 & 9 & 9 & 9 & 7 & 7 & \\
\hline & 0 & 0 & 7 & 0 & 6 & 5 & 8 & 0 & 0 & 5 & 7 & 0 & 0 & 0 & 3 & 8 & \\
Number & 1 & 1 & 2 & 2 & 2 & 2 & 2 & 2 & 2 & 2 & 2 & 2 & 3 & 3 & 3 & 3 & 3 & \\
\hline & 9 & 0 & 1 & 2 & 3 & 4 & 5 & 6 & 7 & 8 & 9 & 0 & 1 & 2 & 3 & 4 & \\
Scores & 0 & 2 & 7 & 8 & 8 & 7 & 9 & 9 & 8 & 9 & 7 & 8 & 8 & 9 & 6 & 8 & 7 & \\
\hline & 3 & 3 & 3 & 3 & 3 & 4 & 4 & 4 & 4 & 4 & 4 & 4 & 4 & 4 & 4 & 5 & 5 & 5 \\
Number & 5 & 6 & 7 & 8 & 9 & 0 & 1 & 2 & 3 & 4 & 5 & 6 & 7 & 8 & 9 & 0 & 1 & 2 \\
\hline \multirow{3}{*}{ Scores } & 8 & 8 & 9 & 8 & 8 & 8 & 8 & 7 & 7 & 8 & 9 & 9 & 8 & 8 & 8 & 8 & 9 & 8 \\
\end{tabular}

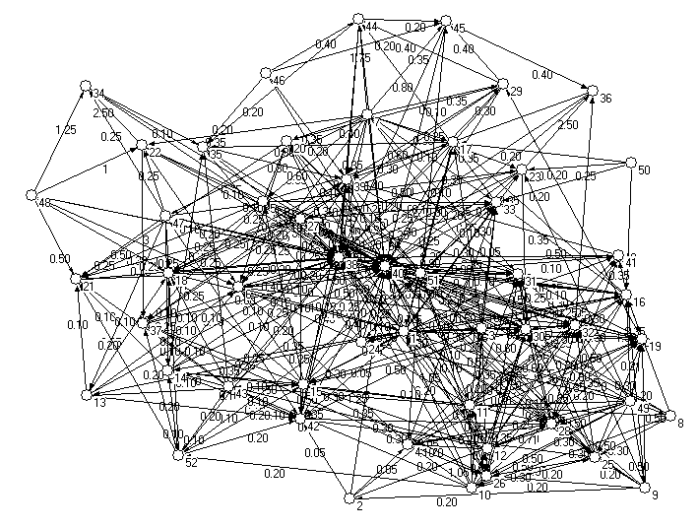

Figure 2. The achievement evaluation network model

Degree Centrality. The degree of a vertex in a network is the sum of weight of all the links connected to it[6]. For grade evaluation network, there are an out-degree $k_{\text {out }}$ and an in-degree $k_{\text {in }}$ which are, respectively, the sum of regulating and regulated relations at the node, as shown in Eq. 1. 


$$
k_{i}^{\text {out }}=\sum_{j=1}^{n} A_{i j}, \quad k_{j}^{\text {in }}=\sum_{i=1}^{n} A_{i j}
$$

Where $A$ is the adjacency matrix of network, $A_{i j}$ is an element of matrix $A, A_{i j} \neq 0$ if there is a link from node $i$ to node $j$, the value of $A_{i j}$ is the weight of edge. The total degree $k_{i}$ of a node $n_{i}$ can be computed by the sum of them, i.e., $k_{i}=k_{i}^{\text {in }}+k_{i}^{\text {out }}$.

Closeness Centrality. Closeness centrality measures the mean distance from a vertex to other vertices. A path in a graph is a sequence of nodes and edges, such that a node belongs only to the edges before and after it, and no nodes are repeated [6]. A path length is the sum of edges weight in the path. The smallest sum of edges weight that have to be traversed in a network to get from one node to another is called the distance between the two nodes and a path through the network that achieves that distance is called the shortest path between the nodes. In a teaching evaluation network, there are in-closeness and out-closeness which are, respectively, measures the distance with regulating and regulated nodes. We define $d_{i j}$ is the shortest path length from $i$ to $j$. Then the closeness centrality of node $i$ is the average of the inverse distances, as shown in Eq. 2.

$$
C_{i}^{i n}=\frac{1}{n-1} \sum_{j(\neq i)} \frac{1}{d_{j i}}
$$

Where $C_{i}^{\text {in }}$ is the in-closeness of node $i$.

\section{Result of Application}

We constructed 35 network model of electronic information science and technology students using the above method and then calculated average of in-degree, in-closeness and graduation design in-closeness of them [7]. These characteristics of network structure can measure the quality of students training from different angles. The in-degree, out-degree, in-closeness, out-closeness, graduation design in-closeness, and grade point average value of 35 electronic information science and technology students as shown in Fig. 3.

As shown in Fig. 3, the distribution characteristics of in-degree and out-degree averages are similar to the grade point averages. The distribution characteristics of graduation design in-closeness averages different from other averages. This illustrates using the structural characteristics of the network are more fully and accurately evaluate the quality of electronic information science and technology students training than the simple average value of the course grades.

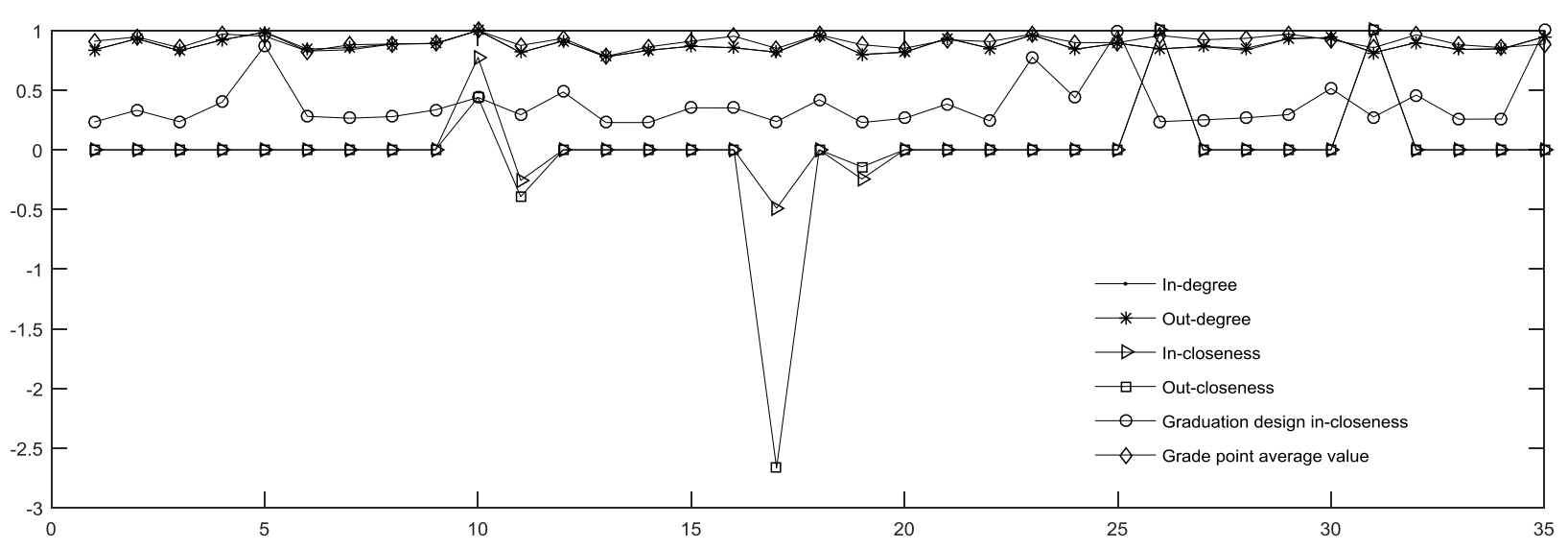

Figure 3. Values of 35 electronic information science and technology students

\section{Summary}

The comprehensive quality evaluation of students is the process of judging the value of the students' quality. It focuses on the students quality optimization and improvement, in order to promote the harmonious development of students physical and mental. The performance evaluation network will be 
useful to evaluate the quality of electronic science and technology students training. Establishing a high quality of students training evaluation network model is directly related to the healthy development of the vocational education.

\section{Acknowledgements}

This work is supported partially by the Key Education Research Project of Beihua university(Grant NO. XJZD2016039), partially by the Jilin Province Science and Technology Development Project(Grant NO. 20170520057JH), partially by the Beihua University Dr. Scientific Research Fund (Grant NO. 199500103).

\section{References}

[1] Hadna, A. H. and Kartika, D. Evaluation of poverty alleviation policy: Can conditional cash transfers improve the academic performance of poor students in Indonesia? Cogent Social Sciences, 2017, 3

[2] Tost, C. M. and Rindermann, H. Development of Benchmarks for the Evaluation of Psychologists' Individual Research Performances Dependina on Academic Age and Subject Area. Psychologische Rundschau, 2017, 68(2): 103-114.

[3] Yadav, R. S., Ahmed, P., Soni, A. K., et al. Academic performance evaluation using soft computing techniques. Current Science, 2014, 106(11): 1505-1517.

[4] Oral, M., Oukil, A., Malouin, J. L., et al. The appreciative democratic voice of DEA: A case of faculty academic performance evaluation. Socio-Economic Planning Sciences, 2014, 48(1): 20-28.

[5] Bahadori, M., Sadeghifar, J., Peyman, H., et al. The relationship between teachers' evaluation scores and the students' academic performance: a case study in Iran. Technics Technologies Education Management-Ttem, 2012, 7(4): 1635-1640.

[6] M.E.J.Newmen. Networks: An Introduction. Oxford University Press, New York, 2010.

[7] Landi, P. and Piccardi, C. Community analysis in directed networks: In-, out-, and pseudocommunities. Phys. Rev. E, 2014, 89(1) 